\title{
Towards a new framework for analysing transnational education
}

Nigel Healey ${ }^{1}$ and Lucy Michael ${ }^{2}$

\begin{abstract}
The well-documented growth of international student mobility has been paralleled by the emergence of so-called 'transnational education' (TNE), in which universities deliver their educational services to foreign students in their own countries, rather than the students travelling to the foreign university to study. While universities have engaged in limited TNE for decades, using a variety of channels from traditional distance-learning to partnershipbased models in which a third party delivers a franchised or validated programme, TNE has expanded significantly over the last 15 years. This paper investigates the increasingly complexity and multidimensionality of TNE partnerships, developing a new three-spectrum framework for classifying this activity. It argues that this new framework provides a more tractable way of classifying and understanding the 'new internationalisation' of higher education.
\end{abstract}

Key words: international higher education, transnational education, offshore education, globalisation of higher education, internationalisation of higher education, international student mobility, GATS and educational services

\footnotetext{
${ }^{1}$ Nottingham Trent University

${ }^{2}$ University of Hull
} 
Higher Education Policy, 2014, DOI:10.1057/hep.2014.17 (this version pre-print / pre-refereeing)

\section{Introduction}

The global market for higher education has grown dramatically over the last 30 years. Higher education has been widely seen by national governments as a way of raising economic productivity and encouraging technological innovation. For students, higher education is a passport to a successful career in the global knowledge economy and significantly enhanced lifetime earnings. A dominant feature of this growth has been a mismatch at national level between supply and demand. In the developing world, the growth in demand has outstripped supply, so ever increasing numbers of (mainly the most affluent) students have been forced overseas to study. In the developed world, particularly countries like the UK, Australia, New Zealand and Canada, where universities have been allowed to charge full-cost tuition fees to international students, supply has expanded to absorb rising numbers of students from the developing world. The latest OECD (2013) figures show $4.3 \mathrm{~m}$ students studying in universities outside their own country, almost all in the high-income OECD countries.

In the last decade or so, a new form of international mobility has begun to take hold in the shape of transnational education (TNE), in which rather than students travelling abroad for study, foreign courses, faculty and even university campuses come to them. The huge growth in online distance education is one example of this new trend. The growing number of leading universities with foreign campuses, notably the University of Nottingham with its campuses in Kuala Lumpur and Ningbo, and the emergence of educational hubs like Dubai International Academic City and Iskandar EduCity which host foreign universities provide other striking examples. 
In principle, TNE opens up a massive potential market for higher education. Because it is generally much cheaper for students to study in their own countries, TNE makes higher education accessible to a new group of students who are either unable (for financial or visa reasons) or unwilling (for family or cultural reasons) to travel overseas to study. TNE holds out the promise of a new market for the universities that engage in TNE and, for the host countries, of increasing the capacity of their locally-based higher education sectors and, through greater competition (and collaboration), improving the quality of incumbent domestic institutions.

The growth of TNE has profound implications for policymakers in both the home and host countries. It has the potential to rebalance the global higher education market, allowing more students to study in their own countries and reducing the costs to developing countries in terms of foreign exchange and 'brain drain'. Understanding these implications depends, in turn, on understanding the organisational forms that TNE can take and the way these are changing over time. This paper reviews the existing typologies that provide the 'lens' through which we view TNE and suggests, based on a discussion of the limitations of these typologies and analysis of approximately 60 case studies of contemporary TNE partnerships, a new approach to categorising TNE.

\section{What is transnational education?}

TNE involves students remaining in their home country while studying at a foreign university (McBurnie and Ziguras, 2009). This form of higher education involves a myriad of delivery channels, from distance-learning to a full international branch campus (IBC), embracing 'any 
teaching or learning activity in which the students are in a different country (the host country) to that in which the institution providing the education is based (the home country). This situation requires that national boundaries be crossed by information about the education, and by staff and/or educational materials' (Global Alliance for Transnational Education, 1997, p1). TNE thus includes 'all types of higher education study programmes, sets of study courses, or educational services (including those of distance education) in which the learners are located in a country different from the one where the awarding institution is based" (Council of Europe, 2002).

\section{The growth of transnational education}

Gauging the growth of TNE is difficult because so few home or host governments collect official statistics on TNE enrolments (Garrett and Verbik, 2004; Altbach, 2007). However, most studies have found evidence of systemic growth in TNE (eg, Bennell and Pearce, 2003; Knight, 2005; Martin, 2007; Humfrey, 2009; Naidoo, 2009). The Observatory on Borderless Higher Education regularly undertakes surveys of different aspects of TNE (e.g., Garrett, 2002, 2004; Garrett and Verbik, 2003a, 2003b; Larsen et al, 2004; Verbik and Merkley, 2006; Lawton and Katsomitros, 2012). These show, for example, a steady growth in the number of IBCs being set up by universities in third countries. A study carried out for the British Council by Bohm et al (2004) concluded that 'the demand [for UK TNE] is expected to grow very considerably: from an estimated 190,000 in 2003 to almost 350,000 in 2010 and then to 800,000 by 2020 ' (p.46). 
Apart from Australia, the UK is one of the only countries which systematically records the number of TNE students taking awards at its own higher education institutions. The national agency responsible for monitoring trends in enrolments, the Higher Education Statistics Agency (HESA), began requiring universities to report the number of students 'studying wholly overseas' (ie, TNE students) in 2007/08. Although the UK and Australia are widely regarded as the market leaders in TNE, as in export education (where they have the highest proportions of international students on campus), the UK data provide one indication of the rate at which the TNE sector is growing more generally.

Figure 1 shows that the UK's TNE numbers have grown by 190\% in just five years, to 571,010 by $2011 / 12$. International (non-UK) enrolments on campus also grew by $27 \%$ over the same period, to reach 435,230 by $2011 / 12$. The faster growth of TNE numbers meant that, from 2009/10, there have been more students studying for UK degrees wholly overseas than on UK campuses. 
Figure 1: International students on-campus vs studying wholly overseas

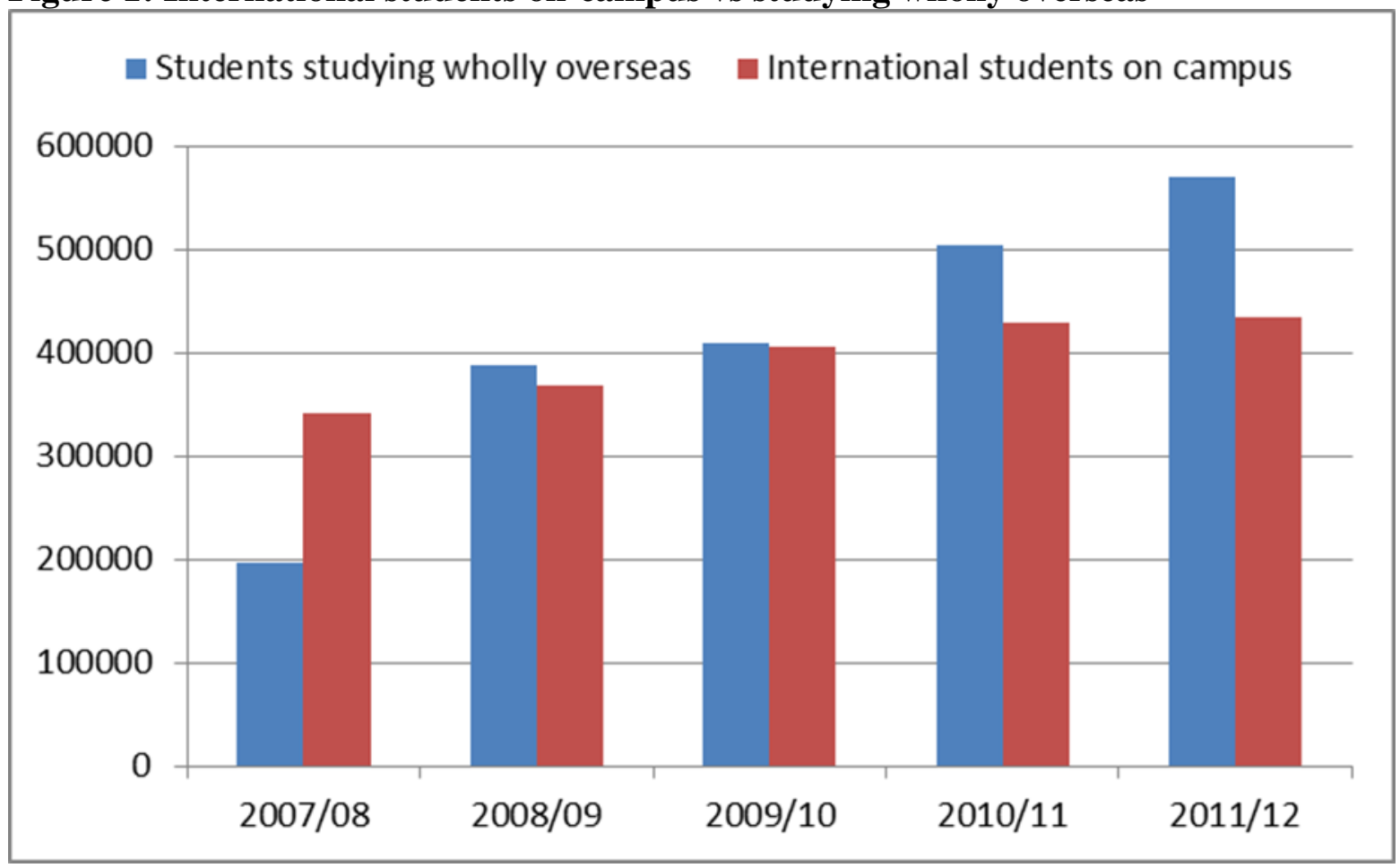

Source: HESA

\section{Current typologies of transnational education}

HESA reports statistics for students studying 'wholly overseas' at UK higher education institutions (HEIs) using three main categories:

1. 'overseas campus';

2. 'distance, flexible and distributed learning'; and

3. 'overseas partner organisation'.

In addition to these three main categories, HESA also allows universities to report students taking the award by 'other' means. Table 1 provides a breakdown of TNE students by type of delivery. It shows strong growth in all forms of TNE delivery, particularly in students studying with 'overseas partner institutions'. The large number of 'other students registered 
at HEIs' mainly relates to students who are studying at a partner institution, but are also registered with the university so that they can access library and other online learning resources.

Table 1: Transnational education by type of delivery

\begin{tabular}{|l|c|c|c|c|c|c|}
\hline & $\mathbf{2 0 0 7 / 0 8}$ & $\mathbf{2 0 0 8 / 0 9}$ & $\mathbf{2 0 0 9 / 1 0}$ & $\mathbf{2 0 1 0 / 1 1}$ & $\mathbf{2 0 1 1 / 1 2}$ & $\mathbf{2 0 1 2 / 1 3}$ \\
\hline Overseas campus & 7,120 & 9,885 & 11,410 & 12,305 & 15,140 & 17,525 \\
\hline $\begin{array}{l}\text { Distance, flexible and } \\
\text { distributed learning }\end{array}$ & 100,345 & 112,345 & 114,985 & 113,065 & 116,520 & 123,635 \\
\hline $\begin{array}{l}\text { Other students registered } \\
\text { at HEI }\end{array}$ & 59,895 & 68,595 & 74,360 & 86,630 & 96,060 & 103,795 \\
\hline $\begin{array}{l}\text { Overseas partner } \\
\text { organisation }\end{array}$ & 29,240 & 197,185 & 207,790 & 291,575 & 342,910 & 353,375 \\
\hline $\begin{array}{l}\text { Other students studying } \\
\text { overseas for HEI's award }\end{array}$ & 70 & 35 & 50 & 125 & 345 & 600 \\
\hline
\end{tabular}

Source: HESA

More generally, the higher education literature classifies TNE either in terms of the provider or in terms of the cross-border movements taking place (eg, courses, students or staff) The first typology, which is widely used, recognises four distinct forms of TNE: distance learning, franchising, validation and an IBC (eg, Bennell and Pearce, 2003; Knight, 2007; Drew et al, 2008). The other is the General Agreement on Trade in Services (GATS) typology, which distinguishes four ways or 'modes' in which a service provider can, in principle, deliver services to a foreign citizen, three of which constitute forms of TNE.

The first typology (the '4F framework') comprises four forms of TNE, effectively splitting students studying at a partner institution between those where the partner is a franchisee and those where the partner is a 'validated centre': 
1. Distance-learning: students study the university's award at distance, with the learning materials supplied to the student via mail or internet. The University of London, for example, has been providing international distance learning degrees since 1858, for most of this time via correspondence courses. Since the advent of the internet in the early 1990s, correspondence, textbook-based courses have been steadily replaced by on-line provision. The recent growth of Massive Open On-line Courses (MOOCs) may presage a new expansion in consortium-based distance learning programmes (Yuan and Powell, 2013; El Ahrache et al, 2013), unleashing a wave of 'disruptive innovation' (Bower and Christensen, 1995).

2. Franchise: the franchisee is a foreign partner authorised to deliver the university's degree on its behalf (Yorke, 1993). With a 'pure' franchise, the degree title, syllabus, teaching materials and assessment are all closely aligned with that of the 'mother' degree on the home campus. In practice, the university may allow variation to accommodate local circumstances, for example allowing the partner to substitute a module on UK business law for one locally designed and assessed to reflect the different legal environment.

3. Validation: the validated centre is a foreign partner which develops and delivers its own programme, but the degree is 'validated' by the university. This validation goes beyond accreditation, since the university is essentially deeming the partner's degree to be equivalent to its own award and is allowing the partner to offer its programme as a degree of the awarding university. Graduates often receive a degree certificate from the university identical to those received by graduates from its home campus, although practice varies in this regard. The partner institution seeks validation normally because it lacks the authority to award degrees in its own right. In most cases, this is because the 
Higher Education Policy, 2014, DOI:10.1057/hep.2014.17 (this version pre-print / pre-refereeing)

partner does not have degree-awarding powers, but sometimes it may be because a foreign university is not authorised to make awards in certain disciplines.

4. International branch campus: an IBC is a foreign satellite campus, which delivers and awards the degrees of the university. In principle, the IBC could deliver the same degrees as it does at home (conceptually equivalent to the IBC being a franchise) or the IBC could develop its own degrees to meet local demand (equivalent to a validated centre). Getting a clear-cut definition is, as Lane and Kinser (2012) note, 'a fairly slippery subject'. The Observatory for Borderless Higher Education regularly surveys and reports on trends in IBCs and has had to continuously adapt its definition of an IBC in response to institutional innovation and changing national regulations (eg, Garrett, 2002; Garrett and Verbik, 2004; Larsen et al, 2004; Verbik and Merkley, 2006; Gore, 2012; Lawton and Katsomitros, 2012).

The second existing typology, based on General Agreement on Trade in Services (GATS) categories, classifies international trade in services by the way in which a service provider can, in principle, deliver services to a foreign citizen:

1. Mode 1 (cross border supply): the service is provided from the territory of one Member into the territory of any other Member.

2. Mode 2 (consumption abroad): in the territory of one Member to the service consumer of any other Member. 
Higher Education Policy, 2014, DOI:10.1057/hep.2014.17 (this version pre-print / pre-refereeing)

3. Mode 3 (commercial presence): by a service supplier of one Member, through commercial presence, in the territory of any other Member.

4. Mode 4 (presence of natural persons): by a service supplier of one Member, through the presence of natural persons of a Member in the territory of any other Member.

In the context of higher education, the GATS categories can be broadly interpreted as:

1. Mode 1 (programme mobility): universities supplying educational services across borders directly to students in their home countries, via distance-learning.

2. Mode 2 (student mobility): students consuming the education services by moving to the country of the university. This is the only GATS mode that is not TNE, since in such export education, the students move to be in the country of the education provider and become classified as 'international students' at the home campus.

3. Mode 3 (institutional mobility): universities supplying educational services to students in their home countries through an in-country service provider. This in-country presence may range from a local college, which offers a university's degrees on a franchised or validated basis (see above), to the university establishing an IBC to teach students in a foreign market.

4. Mode 4 (staff mobility): universities sending staff abroad for short periods to deliver education services to students in their home countries. This form of mobility, known as 'flying faculty' (Seah and Edwards, 2006), involves staff going to the students, but unlike 
Higher Education Policy, 2014, DOI:10.1057/hep.2014.17 (this version pre-print / pre-refereeing)

Mode 3, the staff may be away from their own universities for short periods from a few days to a couple of weeks and the universities have no permanent physical presence incountry, often using rented space in a hotel or partner university.

As Table 2 shows, the GATS typology can be fairly easily mapped against the $4 \mathrm{~F}$ Framework. It might be argued it has less analytic value, since it classifies three very different forms of TNE - franchise, validation and IBC - into one mode. On the other hand, it identifies another form of TNE, the 'flying faculty' model.

Table 2: Mapping GATS against the 4F Framework

\begin{tabular}{|l|c|c|c|c|}
\hline 4F forms & GATS Mode 1 & GATS Mode 2 & GATS Mode 3 & GATS Mode 4 \\
\hline Distance-learning & $\checkmark$ & & & \\
\hline Franchise & & & $\checkmark$ & \\
\hline Validation & & & $\checkmark$ & \\
\hline IBC & & & $\checkmark$ & \\
\hline
\end{tabular}

Typologies provide a way of making the world easier to understand, by grouping things with the same general characteristics together and treating them as if they were the same. Their usefulness depends upon the extent to which clusters of things classified as a particular type actually behave or respond in the same way. This leads to the two interrelated research questions:

1. Given the growth in the number and diversity of TNE partnership around the world, are these two main typologies still a useful way of categorising and understanding such partnerships? 
2. If not, is it possible to develop a more tractable typology to capture this growing diversity?

\section{Methodology}

The problems of exception and ambiguity identified in the two existing typologies called for a methodological approach which directly addresses these issues. We sought to depart from observational analytic descriptions in the first stage of our research design and identify key characteristics of contemporary partnerships through the descriptions of people most closely involved with these arrangements.

To address the first research question, a number of 'experts' were invited to contribute short 500 word case studies of a TNE partnership with which they are directly involved. In this case study, they were asked to describe the features of their partnership arrangements. The structure of the case study was deliberately open, to avoid responses being constrained by preconceived views on the most important features of a TNE partnership. Crucially they were also restricted in word length to facilitate identification of the most important aspects as identified by each participating expert.

The participants were members of the LinkedIn community, all of whom are employed in managing TNE partnerships and known to the authors. Individualised requests were sent to approximately 100 connections with senior roles in TNE. The response rate was approximately $80 \%$, of whom about 40 were able to provide the case studies within the time frame. Of these, 29 were in a usable form, with some discarded because of poor English or 
Higher Education Policy, 2014, DOI:10.1057/hep.2014.17 (this version pre-print / pre-refereeing)

incompleteness. These cases were analysed to see how they fitted against the two main typologies.

In the second stage, the qualitative coding software, NVivo, was used to facilitate multiple coding strategies and recoding as the new analytic categories developed. The summaries which were submitted were diverse in their language and content and, noticeably, in the extent to which the author was familiar with the current thematic and linguistic trends in the academic and policy literature on TNE. The coding strategies constructed for this project took account of this, with thematic rather than linguistic coding employed to construct the evolving nodes. Thematic codes were then refined to create a series of categories which could describe each partnership and facilitate comparative analysis.

The coding of the materials resulted in 15 analytic categories being adopted in the final stage with multiple descriptive nodes within each category to preserve the complexity of the described arrangements. The categories included: Private/Public Status; State Involvement; Initial Model; Model Change; eLearning; Visits to Exporting Institution (including staff and students); Language; Student Population; Subject Range; Research Collaboration and categories separately identifying levels and formats of Undergraduate, Postgraduate Taught and Postgraduate Research provision.

To address the second question, the selection of cases was expanded to include a further 28 case studies derived from QAA Audits of Overseas Provision published between 2010 and 2013. These were analysed using the new adopted categories, firstly ensuring that the categories were inclusive enough for wider use, and secondly, to compare trends across all 57 cases. 
Given the growth in the number and diversity of TNE partnership around the world, are these two main typologies still a useful way of categorising and understanding such partnerships?

The analysis of the 29 case studies revealed the extraordinary diversity and complexity of the TNE partnerships that have developed around the world. Although about half the partnerships involved a UK university, the host countries represented included a wide range that included highly developed countries (eg, Czech Republic, Hong Kong, Italy, Malaysia, Singapore) as well as developing nations (eg, Botswana, Kazakhstan, Madagascar, Uzbekistan).

In terms of the two main TNE typologies, there were numerous examples of partnerships which had characteristics of two or more types. For instance, the University of Northampton has a set of three bilateral partnerships with Vietnamese National University in Ho Chi Min City, Da Nang University and the Hanoi University of Science \& Technology (HUST). Under this arrangement, the Vietnamese universities teach the first part of the Northampton MBA (franchise/mode 3), while the final stage of the taught by Northampton staff on a flying faculty basis (mode 4). The entire courses is supported by an extensive Northampton-based VLE (distance learning/mode 1), while the Vietnamese students come to Northampton for a summer school (mode 2).

In Ghana, the University of Leicester offers a range of distance-learning degrees (mode 1), but these are managed by a local partner which markets the programmes and recruits 
students, provides tutorial support, classrooms and access to facilities (mode 3). Leicester staff regularly travel to Ghana to carry out intensive block teaching to support the distance learning materials (mode 4) while students can opt to study on the Leicester campus (mode 2).

Apart from the serious boundary issues which rob existing typologies of much of their descriptive and explanatory power, these case studies also provide examples of deep transnational partnerships which do not fit neatly into any type. For example, Peking University School of Transnational Law (SLT) operates what it terms a 'sole venture'. SLT has been established as an autonomous organisation by Peking University. It has partnerships with 12 leading law schools from eight countries, as part of which adjunct international faculty operate on a flying faculty basis to develop and deliver a bilingual four-year programme which prepares students for international legal practice. Because the degrees are awarded by SLT, this is not distance learning, franchise, validation or IBC. But the degrees offered depend absolutely on SLT maintaining deep, multidimensional TNE partnerships.

\section{Towards a more tractable typology to capture the growing diversity of TNE}

The diversity evident within contemporary TNE is not easily contained within existing typologies, as our analysis of these case studies shows. There are two key reasons for this: firstly, because the boundaries between delivery modes and contractual arrangements are more blurred, and secondly, because contemporary TNE partnerships are very multidimensional, involving teaching, capacity building and research in diverse blends. Any 
new typology must have sufficient flexibility to allow for the dramatic shifts we see in TNE, while allowing for easy identification and comparison.

In creating a new typology, we have not found it particularly helpful to revisit the drivers for creating TNE partnerships. Our analysis considered the range of factors considered by institutions in entering into partnerships, including cost, market reach, and the promotion of the HEI brand through wider marketing and connection to highly ranked overseas institutions. In addition, we noted the significance of other benefits which encourage institutions to undertake partnerships. These include the possibility of internationalising the HEI through wider global engagement (eg, the recruitment of staff and students to the home campus and the revision of the home curricula) and possibilities for research collaboration with academic staff overseas or access to new customers for research. But whatever the initial aims of a TNE partnership, there is clear evidence in both the QAA reviews and our case studies that external context can drive significant change in the form and content of any partnership, or restrict activity to the extent that concluding a partnership is the sole option available.

There are increasing pressures on exporting institutions to maintain high quality in overseas programmes, in order not to damage the university's global brand, but the costs of doing so are high, and impact of this is may be that institutions are seeking to extract greater value from all partnerships, and reduce the number of partnerships to be monitored. While institutions previously replicated popular activities at a range of sites with an importing partner at each site, the need for greater value from partnerships should predict the multiplication of activities at each site, either through the involvement of more than one 
Higher Education Policy, 2014, DOI:10.1057/hep.2014.17 (this version pre-print / pre-refereeing)

faculty or discipline (replicating the institution itself rather than a single activity) or through other kinds of activity including research.

The 29 case studies we collected also highlight the need for a shift away from an Anglocentric view of the world. The high status of several of the importing public universities involved in these partnerships disrupts the picture of a paternalistic growth model, with 'new' higher education markets dependent on established providers in the UK, Australia or USA to invest in development relationships. It is increasingly clear that heavy investment by state and private providers in creating these new markets has shifted this balance of power. There is also an emerging picture of secondary exports, where importing institutions are replicating their activities in other global regions without any significant additional input from their partners.

We set out below a number of new categories which, we suggest, more completely capture the most distinct characteristics of contemporary TNE partnerships. Analysis of the 57 cases highlighted three important spectrums along which contemporary transnational partnerships are positioned (see Figure 2). The spectrums described below employ an import-export model, where the product is contained within teaching materials and staff expertise. Unlike the existing typologies described above, which concentrate on the location of students and staff and the format of teaching materials, our attempt to set out a new typology draws instead upon the priorities described in our case studies by the participating institutions. The adoption of these spectrums offers the possibility of facilitating comparison with existing typologies and allows recent change in individual partnerships and in broader trends to be mapped more precisely. Further, understanding of these spectrums will allow institutions to identify the position of their partnership arrangements and conceive future flexibilities. 
Figure 2: The spectrums of TNE partnership

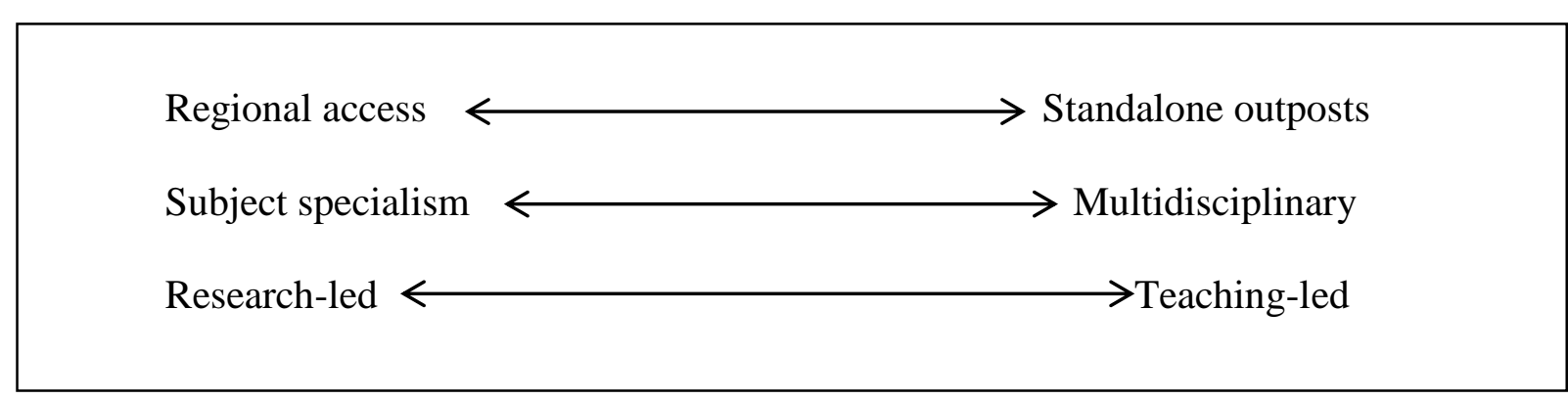

$\underline{\text { Spectrum 1: Regional hubs and stand-alone outposts }}$

In establishing a transnational partnership, an important consideration is the breadth of the target student market. Restrictions on recruitment can mean that HEIs are unable to access students with particular qualifications (eg, China's tier quota system) or unable to recruit because of citizenship or residency criteria. National policy can determine whether a transnational partnership has the potential to be a global hub, recruiting internationally on a par with the home campus of the exporting institution, or whether it can only serve a very specific market in a particular context. This spectrum is defined by the geographical and strategic position of the host institution rather than the number or type of partners to reflect the multiple and overlapping nature of TNE partnerships in established TNE markets.

The clearest examples of regional hubs lie in the IBCs established by Royal Melbourne Institute of Technology (RMIT) Vietnam and University of Nottingham Malaysia. As well as recruiting from a large student market, they can recruit students from overseas who want to study in the region. The University of Nottingham, for example, recruits globally to its Malaysia campus; however, it is worth noting that much smaller numbers of overseas students are attracted to its Ningbo campus, where the population is $94 \%$ Chinese. 
There is clear evidence reported in the case studies of Malaysian efforts to establish public sector HEIs (as well as private HEIs) within a state-supported hub for TNE, facilitating student recruitment from across the region and assuring quality and low-cost education relative to other locations. Malaysian HEIs are for the most part well established institutions, providing a full range of disciplines in teaching and research, sometimes with a reputation which exceeds those of their exporting partners.

However, it is the cost comparator which draws students to Malaysia for a low-cost UK degree: students pay considerably lower costs as international students in Malaysia than they would in the UK, for example, even for equivalent degrees. It is unsurprising then that UK partners exporting to Malaysian HEIs report low numbers of students taking up the opportunity to transfer to the UK institution during their programme. This affects not only Malaysian HEIs, but also transnational partnerships in other regions where lower cost is one of the key attractions for students seeking a UK degree.

At the opposite end of this spectrum, we find partnerships which are so restricted in their form and reach that they can only act as stand-alone outposts for exporting institutions. 'Flying faculty' programmes popular in Hong Kong, exemplified by the University of Salford - LiPACE Open University of Hong Kong partnership, are restricted in their recruitment because students must meet residency requirements to qualify for admission. The potential Chinese market for programmes is therefore inaccessible. Flexibility in recruitment is minimal in these partnerships. The structure within which these partnerships are contained, filling specific identified gaps in provision in designated partnership centres with state approval, simultaneously leaves overseas HEIs unable to significantly change the form of 
their partnerships. Growth is achieved primarily through the expansion of programmes offered, with some limited opportunities for research collaborations or PGR recruitment available depending on the partners involved.

\section{Spectrum 2: Subject specialism versus multidisciplinary partnerships}

A significant number of the QAA reviews analysed refer to the rationalisation of TNE partnerships by UK institutions, with an observed preference to move towards smaller numbers of partnerships that involve a wider range of activities. But while this may be possible and desirable in partnerships with universities and colleges in other regions, where cost of a UK, Australian or US education, or access to these countries, may be restrictive for international students, other drivers for TNE such as capacity-building or research collaboration may favour specialisation. Some universities have also sought to reduce the number of partnerships that might damage institutional reputation because of external risk or internal failure to manage a multiplicity of partnerships simultaneously. Institutional root and branch reviews have therefore favoured concentration on particular activities which can be replicated easily with a small number of providers with high levels of quality assurance, or smaller numbers of wide-ranging institutional partnerships in which quality processes can be replicated across disciplinary boundaries.

This spectrum ranges from partnerships with a single discipline and intensive multiplication of activities through partnerships involving several disciplines to partnerships which replicate a very wide range of the activities of the exporting institution. We might expect to find at the specialist end of this spectrum that institutions prioritise research collaborations, establishing 
access to a particular region, or establishing postgraduate research training compared to a large number of institutions offering only undergraduate education, or taught postgraduate education (mostly MBAs).

Whole-institution replicability creates greater opportunities for staff secondments, development exchanges or employment of local staff trained by the exporting institution, as well as research collaboration, but reduces flexibility in the market more generally. The significant expansion of the subject areas popular in TNE across a very wide range of disciplines makes these partnerships possible and desirable, although business, finance, computing and engineering remain popular areas of study.

'Flying faculty' MBAs and postgraduate business education have long been popular, and continue to be so, being easily replicated in different regions. These include the 'MBA Plus' programmes taught by Northampton Business School and University of Leicester. These partnerships are easily housed within one faculty or department at the exporting institution, and business schools continue to be active in pursuing these kinds of partnerships. Single discipline or single department partnerships are however to be found in almost every discipline in our study, including law, engineering, art business, radiography and across the liberal arts.

Specialisms also allow partnership with private providers outside the higher education sector and greater flexibility in changing labour markets. There is evidence of exporting universities maintaining partnerships with several private specialist providers in the same region simultaneously. However, the flying faculty model draws heavily on staff time at the 
Higher Education Policy, 2014, DOI:10.1057/hep.2014.17 (this version pre-print / pre-refereeing)

exporting institution, as well as decreasing the likelihood of research collaborations with each partner institution as the number of sites grow.

The findings of our analysis show that specialism by discipline (or single faculty partnerships) is not necessarily related to research, postgraduate supervision, or greater contact with the expert staff at the exporting institution. This is a surprising finding. Of the 28 QAA-reviewed institutional partnerships, nineteen concerned specialisation by discipline. However, only nine of these involved direct teaching through flying faculty or joint award arrangements, and another six offered the option to transfer to the UK during studies. Only three of the partnerships involved research collaboration and two related to government capacity-building in nominated areas (technology in Singapore and teacher training in Malaysia).

Of the 29 case studies we collected, fourteen concerned specialisation, but of these only six involved direct teaching (all 'flying faculty') and two offered transfer options. Only two of the partnerships included PGR supervision and only two demonstrated any collaboration in research. Just two of the specialist partnerships were initiated by government invitation (Westminster University in Tashkent and the Asia-Pacific Institute of Information Technology partnership with Staffordshire University). Specialisation does not therefore appear to be particularly related to the development of added value in partnerships.

Along the spectrum we see a number of partnerships which involve business studies and another faculty of the exporting university. Teesside University's partnership with Prague College includes management, business and finance, but also graphic design, media and computing, with research collaboration between Teesside University's School of Art and 
New Media and Prague College. The Middlesex - Mykolas Romeris partnership similarly involves two distinct faculties.

The specialism of the importing institution can restrict the possibility for multidisciplinary partnerships, as with the Malaysian Allied Health Sciences Academy, Da Vinci Institute for Technology Management, or Dongbei University of Finance and Economics. This is not necessarily the case as the Harper Adams - Beijing University of Agriculture partnerships illustrates, involving the areas of food science, retail management and international business.

New ventures exemplify both ends of the spectrum. The DBA programme at Durham University has been the foundation for a joint research centre with Fudan University in China, but no expansion of teaching activities from Durham. Xi'an Jiaotong-Liverpool University reflects institutional replication much more closely and already has 26 joint undergraduate awards in business, engineering, science and culture, planning to add law, public health, demography and Chinese studies by 2016.

However these cases demonstrate that recent wider partnerships across several disciplines are much more likely to produce significant research collaborations. While few partnerships in the QAA reviews involved any research at all, non-specialist partnerships in the QAA reviews were just slightly more likely to have planned or produced research collaborations than specialist. Our case studies, which include more recent arrangements, show that twothirds of the non-specialist partnerships in our new case studies have research collaborations compared to just one in fourteen of the specialist partnerships. 
Spectrum 3: Research-led and teaching-led partnerships

Existing typologies are silent on the role of research in TNE partnerships, although it is clear that the reputation of universities in relation to research is used to good effect in accessing overseas student markets and recruiting partners of good reputation. However, in recent years, HEIs have sought to demonstrate international impact through research collaboration and dissemination. This is a significant way in which exporting HEIs can increase the value of their existing partnerships. There is also evidence of pressure on HEIs importing TNE to use those partnerships to increase their own research capacity. Either party may propose or determine the importance of research collaboration in their working arrangements, but it requires considerable investment on the part of both institutions.

In creating this spectrum, we seek to investigate the ways in which research-led partnerships and teaching-led partnerships differ in their form and content, and the ways in which these serve all of the aims of the partners. This spectrum is at one end characterised by those partnerships that have as their main aim the creation of a sustainable research grouping, which determines all associated activities, and at the other is characterised by partnerships which feature little or no research.

There was little evidence of research collaboration in the 28 QAA reports. Just six of the 28 UK institutions stated research to be a focus of their activities, aimed for the venture to be research-led, or had undertaken significant institutional research collaboration. All six were partnerships with public universities in China, but there was no observable trend in the model of TNE adopted, the provision of undergraduate or postgraduate awards, or participating disciplines. Only one of these was directly related to doctoral awards, with the creation of a 
Higher Education Policy, 2014, DOI:10.1057/hep.2014.17 (this version pre-print / pre-refereeing)

joint Centre for Finance Research in 2010 at Fudan from Durham University's 2007 partnership on DBA provision.

In contrast, the case studies we collected show how important research has become by mid2013. Thirteen of the 29 institutions referred to research collaborations in their descriptions of activity, and most showed evidence of ongoing work in this area. The majority (nine) of the host institutions operate within the public sector. But there is no direct link between research collaborations and teaching arrangements. Only four of these partnerships included postgraduate research supervision and awards.

For branch campuses, research clearly forms a key part of activities, but follows from the primary economic activity of teaching, while in 'flying faculty' partnerships like that of the University of Salford at Open University Hong Kong, research activities also follow teaching activities and are facilitated by staff travel.

At the other end of the spectrum is the partnership between the Sino-British University College Shanghai and the Northern Consortium UK, which has facilitated the establishment of joint research centres between UK partners and Chinese partners, and hosts staff from UK universities at the campus. Joint research centres with high status partners are favoured at the Universiti Teknologi Malaysia (UTM), which hosts the Oxford-UTM Strategic Alliance for Industrial and Applied Mathematics and BLOSSOMS in collaboration with the Massachusetts Institute of Technology (MIT), as well as the Malaysia-Japan International Institute of Technology (MJIIT), designed to stimulate travel and collaboration between 22 Japanese universities and UTM. 
The research spectrum thus highlights significant changes in the relative power positions of partner institutions. Even here the paternalistic growth model which was central to thinking on TNE partnerships is disrupted as elite universities seek to match their resources with similar partners not just to increase their research capacity in methodological or resource terms, but to increase their capacity for dissemination and recognition.

Resource implications for institutions aiming at either end of the spectrum are considerable. For institutions whose partnerships are teaching-led, and involve few other activities, direct income is the most significant considerations in creating, maintaining or ending a partnership. However with increasing pressure on home markets, it is worth noting that universities which undertook partnerships for profit and reputation as a result of these restrictions may find themselves more reliant on partnership income if this is their only significant expansion of activity. Staff involved in teaching report being under pressure to commit to multiple concurrent partnerships in order to increase external incomes through replication of existing programmes at multiple sites (or online), with discernible impact on the quality of teaching and research activities on the home campus.

Universities which seek to build research collaborations through teaching-led partnerships need to consider their strategy carefully. There is evidence of institutional relationships being established with no clear vision for research collaboration, despite these being clearly stated secondary aims of the partnership. Minimal investment or institutional guidance for academic staff involved in the day-to-day work of these partnerships is insufficient to create strong research relationships. The evidence from the case studies shows that research-led partnerships require careful planning and very considerable investment. 
Using this spectrum to view partnership activities can highlight good practice applicable to all partnerships. Rather than see forms of TNE as driving the requirements for sustainable planning and risk assessment, the case studies suggest that there is transferable good practice to be identified. As an example, the framing of partnerships in terms of their capacity to produce something unique is evident in those collaborations which are research-led, but rarely in those at the other end of the spectrum.

Achieving a unique product gives priority to communication, development and review processes within partnership arrangements, shifting the focus away from a risk-averse ethos which emphasises continuity of form and function. Case descriptors from our studies suggest that such a shift could also be usefully pursued even in those partnerships which focus on or prioritise teaching where partners are seeking greater yield from their investments in TNE.

\section{Conclusions}

This paper explores the changing landscape of TNE, highlighting through the use of a wide range of case studies the growing complexity and multidimensionality of TNE partnerships. The blurring of forms of TNE provision are merging as a real challenge to mapping and understanding change in this area, in particular because existing typologies focus on the specific form or location of provision.

The collection and analysis of case studies of contemporary partnerships has helped to expose further shifts in this area which render existing typologies increasingly ill-suited to understanding and describing the landscape of TNE. Using new descriptive case studies 
provided by 29 institutions currently involved in TNE partnerships, we set out to identify the most important features of those partnerships for the institutions involved and those which would be most useful in understanding contemporary trends. Using the results of this qualitative analysis, we explored a further 28 partnerships described in QAA audits of TNE activities conducted in 2010-12.

Three spectrums were adopted to facilitate the mapping of current activities. The first identified the capacity of partnerships to draw on geographical power in recruitment and influence, noting that several TNE partner institutions were situated in highly restrictive markets while others facilitated much wider regional promotion and influence. Engagement in more restricted markets appeared to be significantly influenced by the choice of a high status partner or the presence of a lucrative student market.

The second spectrum captures the divergence of TNE activity between highly specialised partnerships around a single discipline multiplied with several partners, and deep multidimensional TNE partnerships. We identified a distinct trend towards the latter, partly facilitated by growing interest in a wider range of subjects, and partly driven by pressures to internationalise research as well as teaching activities. The sustainability agenda evident now in TNE activity (well documented in observations of rationalisation and review of partnerships in the 28 QAA reports) demands that institutions conceive of greater flexibility within partnerships. This also demonstrates a particular need for our typologies of TNE activity to assume and be able to describe a capacity for change on the part of one or both partners. 
The third and final spectrum which we have employed here describes the role of research in contemporary TNE partnerships, which was an area previously not considered in relation to TNE in the standard typologies. Instead of considering research collaborations, however, as a separate production process, our typology addresses the coherence between research and teaching activities in the new multidimensional partnerships. Institutions who consider both types of activity are more likely to value function over form and are more flexible in their development of activities. Research activities are noted too as being particularly powerful in relaying the institutional ethos of partner institutions into other associated activities partly because it requires much greater discussion of institutional aims in the planning and coordination, but more importantly because it facilitates deeper connections between academic staff groups at each institution. The export or creation of academic ethos may be an important way of distinguishing TNE activities in a market increasingly opened up to affordable online education provision. 
Higher Education Policy, 2014, DOI:10.1057/hep.2014.17 (this version pre-print / pre-refereeing)

\section{References}

Altbach, P. (2007) 'Twinning and branch campuses: the professorial obstacle', International Higher Education, 48: 2-3.

Bennell, P. and Pearce, T. (2003) 'The internationalisation of higher education: exporting education to developing and transitional economies', International Journal of Educational Development, 23(2): 215-232.

Bohm A., Follari M., Hewett A., Jones J., Kemp N., Meares D., Pearce D. and Van Cauter, K. (2004) Vision 2020. Forecasting international student mobility: a UK perspective, London: British Council.

Bower, J. and Christensen, C. (1995) 'Disruptive technologies: catching the wave', Harvard Business Review, 41-53.

Council of Europe (2002) Code of good practice in the provision of transnational education, Strasbourg: Council of Europe. Available from:

http://www.coe.int/t/dg4/highereducation/recognition/code\%20of\%20good\%20practice_EN.a sphttp://www.coe.int/t/dg4/highereducation/recognition/code\%20of\%20good\%20practice_E N.asp [Accessed 14 July 2012].

Dergacheva, D. (2013) 'Blow for UK distance learning in China', Westminster News Online, 28 March 2013. Available from: http://www.wnol.info/blow-for-uk-distance-learning-inchina/ [Accessed 11 March 2014]. 
Higher Education Policy, 2014, DOI:10.1057/hep.2014.17 (this version pre-print / pre-refereeing)

Drew, S., McCaig, C., Marsden, D., Haughton, P., McBride, J., McBride, D., Willis, B. and Wolstenholme, C. (2008) Trans-national education and higher education institutions: exploring patterns of HE institutional activity, London: Department for Innovation, Universities and Skills.

El Ahrache, S.I., Badir, H., Tabaa, Y. and Medouri, A. (2013) 'Massive Open Online Courses: a new dawn for higher education?', International Journal on Computer Science and Engineering, 5(5): 323-327. Available from: http://www.enggjournals.com/ijcse/doc/IJCSE13-05-05-137.pdf [Accessed: 28 June 2013]

Garrett, R. (2002) International branch campuses: scale and significance, Redhill: Observatory on Borderless Higher Education. Available from: http://www.obhe.ac.uk/documents/view_details?id=574 [Accessed 20 September 2012]

Garrett, R. and Verbik, L. (2003a) Transnational higher education, part 1: the major markets - Hong Kong and Singapore, Redhill: Observatory on Borderless Higher Education. Available from: http://www.obhe.ac.uk/documents/view_details?id=703 [Accessed 6 June 2012].

Garrett, R. and Verbik, L. (2003b) Transnational higher education, part 2: shifting markets and emerging trends, Redhill: Observatory on Borderless Higher Education. Available from: http://www.obhe.ac.uk/documents/view_details?id=706 [Accessed 6 June 2012]. 
Higher Education Policy, 2014, DOI:10.1057/hep.2014.17 (this version pre-print / pre-refereeing)

Garrett, G. and Verbik, L. (2004) Transnational delivery by UK higher education, Part 1: data and missing data, Redhill: Observatory on Borderless Higher Education. Available from: http://www.obhe.ac.uk/documents/view_details?id=63 [Accessed 6 June 2012].

Global Alliance for Transnational Education, 1997. Certification Manual. Cited in: Adams, T. (1998) The operation of transnational degree and diploma programs: the Australian case. Journal of Studies in International Education, 2(1): 3-22.

Gore, T. (2012) Higher education across borders: models of engagement and lessons from corporate strategy, Redhill: Observatory on Borderless Higher Education. Available from: www.obhe.ac.uk/documents/download?id=895 [Accessed 20 August 2012].

Healey, N. (2013a) 'Why do English universities really franchise degrees to overseas providers?', Higher Education Quarterly, 67(2), 180-200.

Healey, N. (2013b) 'Is UK transnational education “one of Britain's great growth industries of the future"?,' Higher Education Review, 45(3), 6-35.

HESA, n.d. Statistics - Students and qualifiers at UK HE institutions. Available from: http://www.hesa.ac.uk/content/view/1897/239/ [Accessed 3 March 2013].

Humfrey, C. (2009) Transnational Education and the student experience: a PMI student experience project report, UK Council for International Student Affairs. Available from: http://www.ukcosa.org.uk/files/pdf/pmi/tne_report.pdf [Accessed 25 November 2012]. 
Higher Education Policy, 2014, DOI:10.1057/hep.2014.17 (this version pre-print / pre-refereeing)

Knight, J. (2005) Borderless, offshore, transnational and crossborder education: definition and data dilemmas, Redhill: Observatory on Borderless Education. Available from:

http://www.obhe.ac.uk/documents/view_details?id=35\&gt [Accessed 6 February 2012].

Knight, J. (2007) ‘Cross-border tertiary education: an introduction', in Vincent-Lancrin, S. (ed) Cross-border tertiary education: a way towards capacity development, Organisation for Economic Cooperation and Development and The World Bank, pp. 21-46.

Knight, J. (2011) 'Education hubs: a fad, a brand, an innovation?', Journal of Studies in International Education, 15(3), 221-240.

Lane, J. and Kinser, K. (2012) 'International branch campuses: one definition to rule them all?' Available from: http://chronicle.com/blogs/worldwise/international-branch-campusesone-definition-to-rule-them-all/29051 [Accessed 6 February 2013].

Larsen, K., Momii, K. and Vincent-Lancrin, S. (2004) Cross-border higher education: an analysis of current trends, policy strategies and future scenarios, Redhill: The Observatory on Borderless Higher Education. Available from:

http://www.obhe.ac.uk/documents/view_details?id=49 [Accessed 19 October 2012].

Lawton, W. and Katsomitros, A. (2012) International branch campuses: data and developments, Redhill: Observatory on Borderless Higher Education. www.obhe.ac.uk/documents/download?id=894 [Accessed 22 August 2012]. 
Higher Education Policy, 2014, DOI:10.1057/hep.2014.17 (this version pre-print / pre-refereeing)

Lien, D. (2008) Economic analysis of transnational education, Education Economics, 16:2, pp.149-166

Martin, M., ed. (2007) Cross-border higher education: regulation, quality assurance and impact, Paris: UNESCO. Available from:

http://unesdoc.unesco.org/images/0015/001538/153897e.pdf [Accessed 6 June 2012].

McBurnie, G. and Ziguras, C. (2009) Trends and future scenarios in programme and institution mobility across borders, in Higher Education to 2030 Volume 2: Globalization, Paris: OECD, pp.89-108.

Naidoo, V. (2009) 'Transnational higher education: a stock take of current activity', Journal of Studies in International Education, 13: 310-330.

OECD (2013) Education at a glance 2013: OECD indicators, Paris: OECD. Available from: http://www.oecd.org/edu/eag2013\%20(eng)--FINAL\%2020\%20June\%202013.pdf [Accessed 26 August 2013]

Seah, W. and Edwards, J. (2006) 'Flying in, flying out: offshore teaching in higher education', Australian Journal of Education, 50(3): 297-311.

Wilkins, S. and Huisman, J. (2012) 'The international branch campus as transnational strategy in higher education', Higher Education, 64(5), 627-645. 
Higher Education Policy, 2014, DOI:10.1057/hep.2014.17 (this version pre-print / pre-refereeing)

van der Wende, M. (2003), 'Globalisation and access to higher education', Journal of Studies in International Education, 7(2), 193-206.

Verbik, L. and Merkley, C. (2006) The International Branch Campus - Models and Trends, Redhill: Observatory on Borderless Higher Education. Available from:

http://www.obhe.ac.uk/documents/view_details?id=34 [Accessed 20 November 2012].

Yorke, M. (1993) 'Quality assurance for higher education franchising', Higher Education, 26(2): 167-182.

Yuan, L. and Powell, S. (2013) 'MOOCs and open education: implications for higher education', JISC Centre for Education Technology and Interoperability Standards. Available from: http://publications.cetis.ac.uk/wp-content/uploads/2013/03/MOOCs-and-OpenEducation.pdf [Accessed: 21 June 2013]. 